\title{
FAMILIAL 78XX MALE PSEUDOHERMAPHRODITISM IN THREE DOGS
}

\author{
W. G. D. HARE, R. A. MaFEELY ANd D. F. KELLY* \\ School of Veterinary Medicine, University of Pennsylvania, \\ Philadelphia, Pennsylvania 19104, U.S.A.
}

(Received 21st August 1973)

Abnormal mammalian gonadal and, consequently, genital differentiation usually occurs with heteroploidy and other abnormalities of the sex chromosomes, but can also occur when the sex chromosome constitution appears to be normal.

One expression of the latter situation is in cases of male pseudohermaphroditism with two $\mathrm{X}$, but apparently no $\mathrm{Y}$, sex chromosomes. There have been several reports of this in man (see de la Chapelle, 1972), pig (see Breeuwsma, 1970), goat (see Hamerton, Dickson, Pollard, Grieves \& Short, 1969) and horse (Bornstein, 1967; Generke \& Coubrough, 1970), but only one in the dog (Edols \& Allan, 1968). This paper describes three more cases in closely related dogs with similar anatomical abnormalities.

The propositi were three English cocker spaniels, two (A and B) were littermates, and the third (C) was a sib (Text-fig. 1). They were first seen at 2 months of age showing almost identical abnormalities of the external genitalia; a phallus situated between the hind limbs with a caudally displaced diminutive prepuce, and no scrotal development or palpable testes. Chromosome analyses of peripheral blood leucocytes from the propositi, their dam and sire, and the littermates of Dogs A and B showed the abnormal dogs to be chromosomal females and the others to have matching chromosomal and phenotypic sexes.

Further examination of the propositi was delayed until they were between 7 and 8 months old. Radiological examinations of the external genitalia and derivatives of the urogenital sinus were carried out with the aid of radio-opaque and non-radio-opaque catheters and the injection of air and/or contrast medium. Two urethral passages opening to the exterior were demonstrated: one led through the phallus, ventral to an obvious phallic bone, to open at an external urethral orifice; the other led through the prepuce to the exterior, ventral to the phallus. The two passages joined near the ischial arch to form a common pelvic urethra which extended cranial to the bladder. Just caudal and dorsal to the neck of the bladder, there was a blind pouch connecting with the urethra. On the basis of the laparotomy examinations of the genitalia, this pouch was interpreted as the connection of the genital tract with the urethra by way of a cranial vagina.

Exploratory laparotomies revealed small bilateral abdominal gonads grossly resembling testes, pampiniform plexuses, epididymides, vasa deferentia, uterine

* Present address: Department of Pathology, University of Bristol, Bristol. 
horns, and a uterine body and cervix. The latter connected caudally with the urethra, just caudal to the neck of the bladder. There was no palpable prostate. The gonads and tubular genitalia were removed and dissected. Dog A was partially phallectomized at 9 months.

Microscopic examination showed that the gonads were surrounded by tunica albuginea from which coarse fibrous trabeculae extended into the parenchyma. This consisted mainly of non-canalized, seminiferous tubule-like structures separated by interstitial cells. These vestigial tubules contained uniform Sertoli cells. Neither nuclear activity nor spermatogenesis were seen (Pl. 1, Fig. 1). A rete testis, pampiniform plexus and epididymis were present

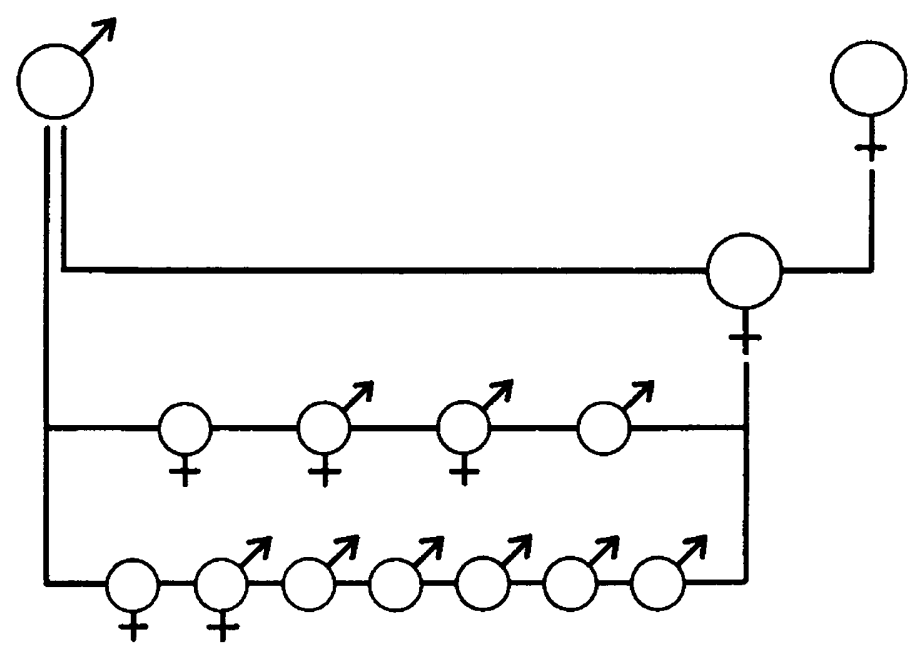

TEXT-FIG. 1. Pedigree showing the composition of the two litters which produced the three canine pseudohermaphrodite propositi.

(P1. 1, Fig. 2). The uterine horns adjacent to the gonads contained several thick-walled structures, the largest of which resembled a corpus uteri. This had a Y-shaped or cruciate lumen surrounded by cuboidal epithelium. Slender glands, lined by similar epithelium, extended into the underlying stroma. Glandular secretion was not seen. Smooth muscle fibres encircled the organ, forming a well-developed myometrium. Some sections of this uterine structure had no apparent lumen and the region internal to the myometrium consisted of loose fibrovascular connective tissue without any epithelial moiety. To one side of the myometrium, there were one or more sections of smaller tubular structures resembling vasa deferentia. These had thick fibromuscular walls and a lumen lined by cuboidal epithelium; the latter frequently formed low folds (P1. 1, Fig. 3). The tubular genitalia were surrounded by loose fibrovascular connective tissue and mesothelium. Sections of the decalcified phallus revealed a typically penile microscopic appearance (PI. 1, Fig. 4).

Chromosome preparations were made from cultures of peripheral blood leucocytes, gonadal tissue and fascia, and directly from bone marrow. The pattern of DNA synthesis in the $\mathrm{X}$ chromosomes of Dog B was studied by adding $0.35 \mu \mathrm{Ci}$ tritiated thymidine (specific activity $2.0 \mathrm{Ci} / \mathrm{mmol}$ ) (New 
PLATE 1

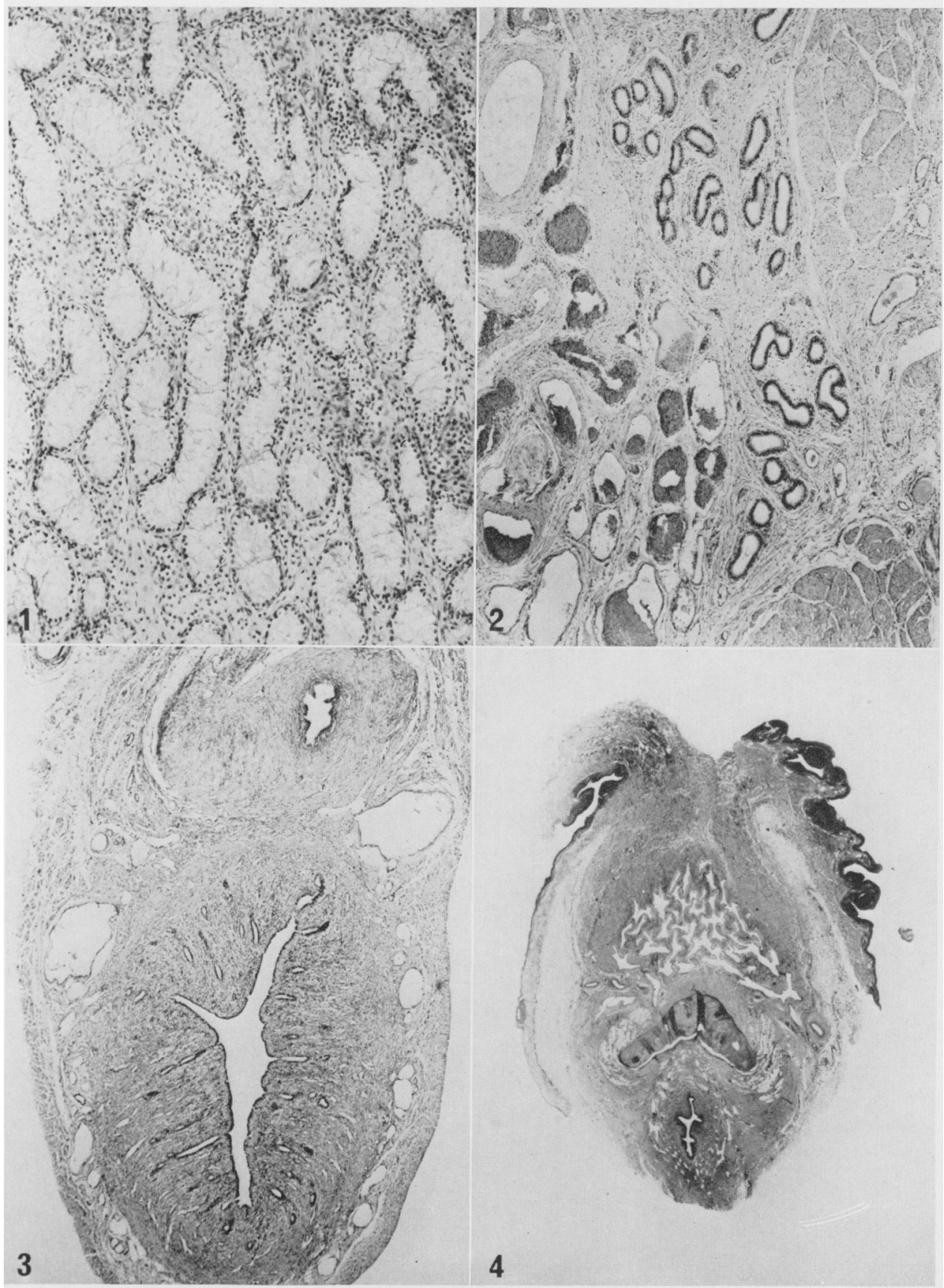

Fig. 1. Section of canine gonad showing interstitial cells and solid tubules lined by Sertoli cells. H \& E, $\times 104$.

FIG. 2. Section of canine gonad with epididymis and pampiniform plexus. H \& E, $\times 44$.

FIG. 3. Section of tubular genitalia with vas deferens above and uterus below from canine pseudohermaphrodite. Elastic-van Gieson $(E V G), \times 44$.

FIG. 4. Section of phallus with urethra, os penis and corpus cavernosum penis from canine pseudohermaphrodite. EVG, $\times 3$. 
England Nuclear Corporation, Boston, Massachusetts) per $\mathrm{ml}$ of culture medium $3 \mathrm{hr}$ before harvesting, followed by $0.01 \mu \mathrm{Ci}$ colcemid (Ciba Pharmaceutical Products, Inc., Summit, New Jersey) per ml of culture medium $2 \mathrm{hr}$ before harvesting.

The results of the chromosome analyses are given in Table 1 . There was no apparent $\mathrm{Y}$ chromosome in any of the 540 cells examined. The peripheral blood leucocyte data in each case are based on two blood samples taken approximately 4 months apart. The autoradiographic studies on the peripheral blood leucocytes showed a number of cells in metaphase with a late-labelling $\mathrm{X}$ chromosome.

Sex chromatin was studied on buccal smears prepared and stained with $1 \%$ cresyl echt violet (Culling, 1966). Approximately $35 \%$ of the cells were sexchromatin positive.

Table 1. Chromosomal analyses of tissues from three male pseudohermaphrodite dogs

\begin{tabular}{l|ccccc}
\hline \multicolumn{1}{c|}{ Tissues } & \multicolumn{5}{c}{ No. of cells } \\
& Dog $A$ & Dog $B$ & Dog $C$ & $X X$ & $X Y$ \\
\hline Peripheral blood & 72 & 62 & 100 & 234 & 0 \\
$\quad$ leucocytes & 24 & 7 & 82 & 113 & 0 \\
Fascia & - & 53 & 13 & 66 & 0 \\
Bone marrow & 6 & -22 & 63 & 69 & 0 \\
Left gonad & - & 144 & 294 & 540 & 0 \\
$\quad$ Right gonad & 102 & & & & \\
$\quad$ Total & & &
\end{tabular}

With the exception of a cocker spaniel, which was found to have a female sex chromosome constitution (Edols \& Allan, 1968), all other male pseudohermaphrodite dogs for which the genetic sex has been studied have been reported either as chromatin negative (Schultz, 1962; Brown, Swanton \& Brinkhous, 1963) or as having an XY sex chromosome constitution (McFeely, Hare \& Biggers, 1967).

The simplest theoretical interpretations of the anatomical abnormalities described here are either (1) that the fetal testis-like gonads secreted inadequate amounts of Müllerian-inhibiting and Wolffian-stimulating (masculinizing) hormones (Jost, 1965), or (2) that normal amounts of fetal testicular hormones were secreted but there was a lack of sensitivity on the part of the sex primordia (Jost, 1955), due possibly to the modifying effects of the female genotype (see Burns, 1956).

The ability of testicular tissue to develop in the apparent absence of a $\mathrm{Y}$ chromosome is widely recognized in man, pig and goat, and has also been reported in the horse and dog. Some of these cases may have had an undetected $\mathrm{Y}$ chromosome either in the form of an XY-cell mixoploid or translocated onto an $\mathrm{X}$ chromosome or an autosome. In the cases reported here, however, the occurrence of normal male and female littermates, together with the absence of a Klinefelter-like phenotype, would discount Y-translocation, and the occurrence of almost identical anatomical abnormalities would support the failure to demonstrate mixoploidy. 
These observations taken together with the mode of inheritance which is consistent with the action of several genes on the sex chromosome or a single autosomal recessive gene, support the hypothesis for sex determination in mammals advanced by Hamerton (1971). In brief, this is-that the genes controlling both medullary and cortical stimulation of the indifferent gonad are on the $\mathrm{X}$ chromosome (as suggested by Polani 1962; McFeely et al., 1967) and that the gene for medullary stimulation, or its operator, is normally activated by a controlling centre on the $\mathrm{Y}$ chromosome. A further suggestion, based on the evidence for a genetic cause in man, pig and goat, is that in nonmixoploid intersexes and sex reversals, there is a sex-limited autosomal recessive gene which can modify the controlling centres on the $\mathrm{X}$ chromosome in the female and the $\mathrm{Y}$ chromosome in the male. In $\mathrm{XX}$ male pseudohermaphrodites, the autosomal gene would simulate the action of the $\mathrm{Y}$ chromosome-controlling centre and activate the gene on the $\mathrm{X}$ chromosome controlling medullary stimulation. The sex distribution in the two litters reported here (Text-fig. 1) can be explained if the sire was homozygous and the dam heterozygous for a single autosomal recessive gene expressing itself only when homozygous in the female. Thus, the situation would be similar to that in the goat. Unfortunately, the sire and dam were not available for further studies.

This work was supported by U.S.P.H.S. grant HD-04355. The assistance of Dr W. H. Rhodes, Dr Paul Berg and Mrs Joanne Kushall is gratefully acknowledged.

\section{REFERENCES}

BorNSTEIN, S. (1967) The genetic sex of two intersexual horses and some notes on the karyotype of normal horses. Acta vet. scand. 8, 291.

Breeuwsma, A. J. (1970) Studies on intersexuality in pigs. Ph.D. thesis, Research Institute for Animal Husbandry "Schoonoord". Ziest, The Netherlands.

Brown, R. C., Swanton, M. C. \& Brinkrous, K. M. (1963) Canine hemophilia and male pseudohermaphroditism: cytogenetic studies. Lab. Invest. 12, 961.

Burns, R. K. (1956) Hormones versus constitutional factors in the growth of embryonic sex primordia in the opossum. Am. F. Anat. 98, 35.

Culling, C. F. A. (1966) Staining affinities and cytochemical properties of the sex chromatin. In: The Sex Chromatin, p. 91. Ed. K. L. Moore. Saunders, Philadelphia.

de la Chapel.ze, A. (1972) Nature and origin of males with XX sex chromosomes. Am. F. hum. Genet. 24, 71 .

Edols, J. H. \& Allan, G. S. (1968) A case of male pseudohermaphroditism in a Cocker Spaniel. Aust. vet. 7. 44, 287.

Generke, W. H. \& Coubrough, R. I. (1970) Intersexuality in the horse. Onderstepoort F. vet. Res. 37, 211.

Hamerton, J. L. (1971) Sex determination and the significance of sex chromosome abnormalities in man and mammals. In: Human Cytogenetics, Vol. 2, p. 169. Ed. J. L. Hamerton. Academic Press, New York and London.

Hamerton, J. L., Drckson, J. M., Pollard, G. E., Grueves, S. A. \& Short, R. V. (1969) Genetic intersexuality in goats. 7 . Reprod. Fert. Suppl. 7, 25.

Josr, A. (1955) Biologie des androgènes chez l'embryon. $111^{\circ}$ Réunion Endocrinologie, p. 160. Masson, Paris.

Jost, A. (1965) Gonadal hormones in the sex differentiation of the mammalian fetus. In: Organogenesis, p. 611 , Eds. R. L. DeHaan and H. Ursprung. Holt, Rhinehart and Winston, New York.

McFeely, R. A., Hare, W. C. D. \& Biggers, J. D. (1967) Chromosome studies in 14 cases of intersex in domestic mammals. Cytogenetics, 6, 242.

Polani, P. E. (1962) Sex chromosome anomalies in man. In: Chromosomes in Medicine, p. 73. Ed. J. L. Hamerton. Heinemann, London.

Schultz, M. G. (1962) Male pseudohermaphroditism diagnosed with the aid of sex chromatin technique. J. Am. vet. med. Ass. 140, 241. 